\title{
Deliberation on the Spirit of the National Culture Caused by the Film Wolf Warrior
}

\author{
Yani Zong \\ Xi’an International University, Xi'an, Shaanxi, 710077
}

\begin{abstract}
Keywords: The Film WOLF WARRIOR; Spirit of National Culture; Deliberation
\end{abstract}
\begin{abstract}
Film is an indispensable part in the current media industry. It enriches the spirit world of the people, and some excellent films could produce some emotional vibes of the audiences. There are lots of excellent films which produce some emotional reactions of the audiences such as THE WOLF WARRIOR, THE FOUNDING OF A REPUBLIC etc. This kind of films could trigger the national cultural spirit of the people and let the people deliberate on the spirit of the national culture. The film WOLF WARRIOR is the very film that is with this feature. In the film, the leading actor is romantically shaped as a super hero, and in this point, this film adopts the filmic feature of the Hollywood style. But the difference between this film and the Hollywood film is that although the leading actor in this film shows himself as a super hero, he also shows the unswerving fighting spirit of the contemporary Chinese soldier. The military spirit shown in this film not only causes the emotional reactions of the people in reality, but also gives some inspirations on the cultivation of the contemporary military spirit. This thesis is mainly from the perspective of film literature, then deeply analyzes the film WOLF WARRIOR, and deliberates on the national cultural spirit caused by the film at last.
\end{abstract}

\section{Introduction}

In the film and television filed, film is a kind of comprehensive art, which perfectly combines the art of time with the art of space, and provides not only the "aesthetic feeling" to the audience, but also the deliberation of the spiritual and emotional world. The film WOLF WARRIOR is a 3D action military film, and the first 3D action military film in China. It is directed by the famous action star Wu Jing who also is the leading actor in the film. What's more, some famous stars are also in this film, such as Yu Nan, Ni Dahong, Scott Edward Adkins, etc. It takes seven years to accomplish the production of this film. In this movie, the director uses many kinds of artistic methods, such as dialogue and action, etc. These artistic means present the vivid pictures that the Chinese soldier fights against criminals so as to catch them in the frontier of China. When watching the film, audience can feel the Chinese cultural spirit conveyed by these filmic expressing methods so as to strengthen the sense of identity of the Chinese cultural spirit. Because of the national cultural spirit in the film, the box office of the film had reached 100 million Yuan for three days after its first public showing. What's more, this film unfolds a heroic figure that is usually shown in the film of the Hollywood, but from the end of this film, this film also belongs to the films which praise the collectivism; at the same time, the film gives the audience the feeling that China is increasingly becoming stronger, which satisfies the needs of the audience in spirit, emotion, and psychology, and allows the audience highly identify with the national cultural spirit.

\section{The Breakthrough and the Innovation of the Film WOLF WARRIOR}

The film WOLF WARRIOR is an excellent military action movie, and it influences the traditional military movie a lot. In the contemporary life few people pay attention to the military film, but this film provides a different feeling to the audience; it is not the same as the previous military movie which highlights the function of collectivism. In the film, while it praises the collectivism in the end, it adds some new elements all the time, for example, the individualistic heroic image of the protagonist in the movie. With respect to the technique of expression, this film 
transforms the previous military movie into the blockbuster, and unfolds the Chinese soldiers' firm and unyielding character to the audience's spiritual world. In the film circle, some scholars point out that the movie WOLF WARRIOR caters for the audience's aesthetical standard, and innovates the traditional military movie at the same time, and then combines lots of filmic elements together. It is a kind of important trial of the military movie, so it achieve a great success [1]. In this movie, the heroism, the wonderful but real action, the fighting scenes which are almost actual combat, the modern military equipments, and the heroic element which may be learnt from the Hollywood movie all promote the movie to be wonderful. In addition, the breath-taking fight in the film greatly shocks the audience and has the feature of violence aesthetic.

There are many strong themes in the previous military movies, but they are not with commercial element with the consequence that military movies usually do not tend to be concerned. However, in the movie WOLF WARRIOR, the director adds strong commercial elements to the film. In the ending phase of the movie, the hero named Leng Feng and his captain go away fast by car freely, and this is the common scene in the movie of the Hollywood. There also are the similar scenes in the early commercial movie of China; actually, this kind of filmic frame belongs to the commercial elements of movie. When these elements come into the proper filmic frame, it could acquire the audience's high approval of the value that the movie presents. From this point, the national cultural spirit, which the producer wants to be shown in this military movie, also could deliver to the audience by the movie that has integrated the commercial elements. The great success of the film WOLF WARRIOR not only let the producer find the new methods of producing the military film which has a certain theme, but also inspires the audience's interest in the military movie with the result that the military movie would have a prosperous prospect.

In Hollywood movies, the hero is usually endowed with a sense of mission that other people would not have. In the meantime, the protagonist's personal ability is stronger than others. Such as the films like Superman, Captain America, and Spiderman etc, these super heroes in these films are all endowed with the special missions and the individualistic heroism. When the producers of these Hollywood movies want to present these super heroes' images, they all turn to some artistic expressions such as dialogue, appearance, and character, etc [2]; at the same time, they also could add some commercial elements to the movie so as to strengthen the individualistic heroism of the leading actors. In the film WOLF WARRIOR, the leading actor also has this feeling of mission, although the protagonist named Leng Feng who has not the same super ability such as the others, he is endowed with the special feeling of mission in the movie, and this feeling of mission is the expression of the Chinese national cultural spirit, which is the spiritual expression of the Chinese soldier, and the spirit that the audience needs at the bottom of their hearts. There is an extreme close-up on the oriflamme and the armlet in the end of the film, and the dialogue that "I fight for China”, these totally inspire the patriotism of the audience, and endow the leading actor Leng Feng with more divine mission.

\section{The National Cultural Spirit Triggered by the film WOLF WARRIOR}

There are great differences between the previous military movies and the film WOLF WARRIOR. The previous military films usually emphasize the collectivism and the discipline. However, with the development of the times, the aesthetic standard of the people has changed and they tend to prefer the spirit of individualistic heroism. In the film WOLF WARRIOR, the individualistic heroism presented by the leading actor Leng Feng attracts the audience so much that they feel they were the hero in the movie, and feel the patriotism of the leading actor clearly, which greatly strengthens the sense of identify of the audience's patriotism. The national cultural spirits that are triggered by the film are as below:

In the film WOLF WARRIOR, there is a scene about the military maneuver tells that the WOLF WARRIOR Special Force, where Leng Feng is in service, is attacked by the opponent suddenly so that lots of Leng Feng's battle companions are killed, many of soldiers in the Special Force become distressed, all the soldiers determine to eliminate the enemy and defend their motherland, at the same time, to seize back their lost reputation. In this plot, the brigade commander says that the 
borderline is the best beautiful thing in the soldiers' eyes, it is the place the solders should try their best to defend even though their life can be in danger. After the commander's words, all the members of the Special Force change their armlets to the special ones that represent the People's Republic of China, and then they shout out the excited words that----Anyone who offends China will be killed no matter where they are [3]. This kind of expression of words totally shows the Chinese soldiers' faith of loyalty and patriotism. To the audience, they could easily be attracted and give some praises to the movie with this excited national spirit.

With regard to the national cultural spirit of China, the intrepid fighting spirit always is an important expression, especially as is shown in the army, Chinese soldiers keeps the intrepid fighting spirit all the time. In the film WOLF WARRIOR, this kind of spirit is totally presented. A scene in the film gives the audience the story that the criminal set a trap with the badly wounded soldier who is the teammate of Leng Feng in order to kill Leng Feng. According to the introduction that Leng Feng's father also had met this kind of situation similar to the dilemma his son is meeting at present. Although the father and the son all have met the similar dilemma, their selections are different. The father chooses to kill his teammate so that the teammate could die without physical and mental suffering from the enemy, while his son struggles to rescue his partner by his cute observational ability and the intrepid fighting spirit. In the end, Leng Feng has not only rescued his partner successfully, but also killed the enemy near the borderline on his own.

In the film WOLF WARRIOR, when the leading actor Leng Feng meets a group of enemy who are illegally armed, he shouts to the enemy "come on, come on" without any shrinking back and begging for mercy, these completely show Leng Feng's national spirit of tenaciously striving to succeed. It is the very spirit that the Chinese soldier fights for the country with the heroic manner of fighting until the last drop of blood and the unyielding fighting style [4]. In addition, this spirit not only exists in the Chinese army, but also exists in every body of the Chinese people, and also it is this spirit of tenaciously striving to succeed that the people all over the word give their respects to China.

The spirit of taking death calmly is one of the expressions of the Chinese national cultural spirit. In the film WOLF WARRIOR, not only the leading actor has this kind of spirit, so do all the Chinese army. The spirit of taking death calmly is the expression of the soldier's patriotism. In the film, there are many scenes that praise this kind of spirit, it is with the help of this kind of romantic method that the audience hopes that they also could have this spirit. Hence, the emotional exchange between the leading actor of the film and the audience gets achieved.

\section{Conclusion}

To sum up, in the film WOLF WARRIOR, the leading actor Leng Feng (acted by Wu Jing) is shaped as a hero, and a riffraff as well. In the story, the producer shapes all the roles successfully, and every role has their special character. Ihe story goes on smoothly and the audience feels reasonable. At the same time, the plots are full of the Hollywood style; the producer adds lots of commercial elements to the film, so the audience feels as if they were the people in the story. What's more, in the movie not only the personal characters of Leng Feng's teammate, who is persecuted to death, but also the malicious drug trafficker, must be expressed by the artist methods well such as the action, the dialogue and so on. In the film, the dialogue that---- "Anyone who offends China will be killed no matter where they are” contains the national cultural spirit exactly, and with the unfolding of this national cultural spirit, the audience's spiritual needs are satisfied, and the national cultural spirit is deeply planted into the audience's bottom of heart.

\section{References}

[1] Ding Yang. Try to Discuss the Aesthetics of the Chinese Realism Movie[D]. 2013.

[2] Peng Siqun. Philosophical Deliberation on the Cultural Spirit, National Spirit, and the Spirit of the Times[J]. Journal of Tongling Vocational \& Technical College, 2008, (03):50-51. 
[3] Xu Yanrong, Zhang Shushan. The Chinese Movie That under the Soak of the Nnational Cultural Spirit----Deliberation on the Teaching of Chinese Filmic History[J]. Movie Review, 2008, (05):71-73.

[4] Shi Gexin. Deliberation on the Relationship between the National Spirit and the Advanced culture[J]. Journal of Historiography, 2006, (01):5. [2017-08-25]. 